\title{
Erythema Multiforme: A Mysterious Lesion!
}

\begin{abstract}
The term "erythema multiforme (EM)" includes a wide and controversial variety of clinical expressions at the present time. This study revises the EM minor characteristics according to the most important publications found in literature. EM is a distinct dermatologic hypersensitivity pathology characterized by cutaneous or mucous lesions, and eventually, it can also involve both. In the EM minor, only one mucous membrane is affected and usually is the oral mucosa. When occur in the skin, the lesions usually appear symmetrically in the extremities and may exhibit several forms; hence, the name EM, in a target form, could be continuous or recurrent and none additional systemic involvement is present for both cases. Nowadays, many authors separate etiologically the several manifestations of the EM spectrum. However, no clinical definition is still accepted thoroughly, making more difficult the comparisons of etiological and clinical aspects, histopathological studies, and therapeutic protocols. For the present work, we tried to elucidate through an extensive literature revision, some historical and current aspects of EM, focusing mainly the EM minor and its frequent association to herpes simplex virus, with their diagnostic characteristics and current therapeutics, to facilitate the physician understanding, and to favor future researches about this mysterious disease.
\end{abstract}

Keywords: Epidermal necrolysis toxic, herpes-associated erythema multiforme, herpes simplex virus, Stevens-Johnson syndrome

\section{Introduction}

Erythema multiforme (EM) is an acute, recurrent, self-limited, inflammatory mucocutaneous disease that manifests on the skin and often on the oral mucosa. The skin lesions may take several forms such as macules, papules, vesicles, bullae, and hence the term "multiforme". The classic skin lesion consists of central blister or necrosis with concentric rings of variable color around it named typical "target" or "iris" lesion that is pathognomonic of EM. Exact etiology is not known, consider to be a hypersensitivity reaction, and the most common inciting factors are infection, particularly with herpes simplex virus (HSV) or drug reaction to nonsteroidal anti-inflammatory drug (NSAIDs) or anticonvulsants. Adverse drug-related skin reactions that have a frequency above $1 \%$ are urticaria, angioedema, photosensitivity, fixed drug eruptions, EM, Stevens-Johnson syndrome (SJS), and toxic epidermal necrolysis (TEN). Historically, fulminant forms of EM were labeled SJS and TEN (Lyell disease). However, more recent data suggest that EM is etiopathologically

This is an open access journal, and articles are distributed under the terms of the Creative Commons Attribution-Non Commercial-ShareAlike 4.0 License, which allows others to remix, tweak, and build upon the work non-commercially, as long as appropriate credit is given and the new creations are licensed under the identical terms.

For reprints contact: reprints@medknow.com distinct from those two latter conditions, and they are discussed separately. ${ }^{[1]}$

\section{Epidemiology}

Although it can happen at any age, EM minor is more common in patients among 20 and 40 years, in spite of more than $20 \%$ of the cases affect children after 3 years old and adolescents. ${ }^{[2]}$ Recurrences occurs in $37 \%$ of the cases, and they usually happen in the spring and autumn season, with clinical severity increase of the attacks. ${ }^{[2-4]}$ In agreement with Farthing et al., ${ }^{[3]}$ EM minor may be recurrent and the oral cavity is frequently affected. The prevalence of oral EM minor varies from $35 \%$ to $65 \%$ among patients with skin lesions. However, in patients where EM minor was diagnosed by oral lesions, incidence of skin lesions ranged from $25 \%$ to $33 \%{ }^{[5]}$ An interdisciplinary study reported that $70 \%$ of cutaneous recurrent EM minor patients had an oral involvement, comprising of multiple, large, shallow, extremely painful, and debilitating ulcers, with entire oral mucosa affected in over $20 \%{ }^{[3]}$ The oral lesions have predilection for the vermilion border of the lips and the buccal mucosa, mostly sparing the gingiva. ${ }^{[5]}$ How to cite this article: Shrihari TG, Shetty SR.
Erythema multiforme: A mysterious lesion!. Indian J
Med Paediatr Oncol 2018;39:363-7.

\section{TG Shrihari, Shishir Ram Shetty ${ }^{1}$}

Department of Oral Medicine and Radiology, Krishnadevaraya College of Dental Sciences and Hospital, Bengaluru, Karnataka, India, 'Department of Oral Medicine and Radiology, Gulf Medical University, Ajman, UAE

Address for correspondence: Dr. TG Shrihari,

Department of Oral Medicine and Radiology, Krishnadevaraya College of Dental Sciences and Hospital, Bengaluru - 562 157, Karnataka, India.

E-mail: drshrihariomr@, gmail.com

Access this article online Website: www.ijmpo.org DOI: 10.4103/ijmpo.ijmpo_31_17 Quick Response Code:

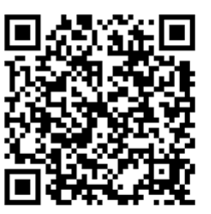




\section{Etiology and Pathogenesis}

Even though many factors may be involved in the EM, frequently the basic cause of the disease is unknown. In contrast to Skin EM, which is mainly caused by systemic drugs (principally anticonvulsants, sulfonamides, NSAIDs, and antibiotics) and HSV infection, the etiological agents remain obscure in many oral EM cases. Many studies based on cohorts with cutaneous involvement found a relation between EM and HSV infection which has not always established in studies of stomatological cohorts. HSV DNA has been demonstrated in cutaneous and oral lesions, but the role of HSV in the etiology of oral EM remains uncertain. Some studies show that recurrent EM precipitated by sun exposure is associated with HSV infection in $65 \%-70 \%$ of cases and is known as herpes-associated EM (HAEM), both by history of 1-3 weeks before onset of EM, seropositivity for HSV antibodies, and identification of HSV antigens. Approximately $87 \%$ had concurrent Recurrent herpes labialis (RHL). Using polymerase chain reaction (PCR) techniques, HSV gene products have been identified in $71 \%-81 \%$ of cases of recurrent EM. For nonrecurrent EM, this falls to $27 \%$. It is postulated that HSV antigens incite a T-cell-mediated delayed-type hypersensitivity reaction that generates Interferon $-\alpha$, with the amplified immune system recruiting more T-cells to the region. Cytotoxic T-cells, natural killer cells, and/or cytokines destroy the epithelial cells. ${ }^{[1]}$ On the other hand, drug-induced EM was a mechanistically definite condition in which keratinocytes were positive for tumor necrosis factor-ALFA, a sign of toxic injury. These findings furnish the mechanistic support for prior clinical and histopathology observations that these are separate conditions. ${ }^{[6]}$

Other viral, bacterial, fungal, and protozoal infections and medications may also play a role. Because it is a hypersensitive reaction, HSV is not cultured from lesions. ${ }^{[1]} \mathrm{A}$ genetic predisposition to EM minor may be of importance, as suggested by the familial tendency that has been documented. Certain Human leukocyte antigen (HLA) phenotypes may predispose the host to develop this disease in response to an extent of stimuli. HLA-B62 is found in a high proportion in patients with recurrent EM minor and also in patients with recurrent HSV infection. ${ }^{[7]}$

Even though some rare cases of EM minor can be idiopathic, ${ }^{[2]}$ several etiological factors can be associated with its development. Some medicines or topic contactants, food allergy, hepatitis B virus, HSV, and Epstein-Barr virus infections, coxsackievirus infections, mumps, streptococcal and mycoplasma pneumonia (Eaton agent) infections, coccidioidomycosis, Candida, histoplasma, Yersinia, radiation (mainly the ultraviolet [UV]), dermatomyositis, leprae, diseases as lupus erythematosus, bowel disease, Wegener's granulomatosis, renal carcinoma, physical agents (Koebner phenomenon), and acute alcoholism are mentioned as etiological factors. A recent report also has proposed that rare cases of EM may be induced by cytomegalovirus infection. There is some evidence that sufferers have a defect in delayed-type hypersensitivity and a reduced lymphocyte response. The pathogenesis of EM minor may involve an immune complex-mediated vasculitis. ${ }^{[8,9]}$

\section{Herpes-associated Erythema Multiforme}

The literature has suggested a strong association between HSV and EM, especially recurrent EM. ${ }^{[10]}$

Investigations associating HSV (1 or 2) as an etiological factor of EM minor were earlier described in the decades of 30 and 40 of the previous century. ${ }^{[2]}$ The HAEM is a recurrent disease that can be precipitated by sun exposure and does not progress to SJS. ${ }^{[1]}$ Even in the absence of a clear clinical history of HSV infection, subclinical HSV is likely the precipitating factor, as confirmed by the PCR analysis of HSV. Before PCR studies were performed, it was evaluated that $15 \%-65 \%$ of EM are secondary to HSV infection and that a significant proportion of idiopathic EM was related to subclinical HSV infection. PCR studies actually have been able to detect HSV DNA in 36\%-75\% of EM ${ }^{[1]}$ Suggesting an explanation for the physiopathology of these lesions, some authors hypothesized that HSV is engulfed by macrophages at the site of the HSV lesion that precedes HAEM development. These phagocyte cells are nonpermissive for HSV replication, resulting in a degradation of the viral DNA and dissemination of fragments to peripheral skin. ${ }^{[12,13]}$ HSV DNA fragments with a whole DNA polymerase gene $(\mathrm{Pol})$ are deposited at different anatomical skin sites where Pol is expressed. Activated T-cells are recruited to the site of Pol expression resulting in an inflammatory cascade. ${ }^{[14]}$ The skin from HAEM lesions was positive for the viral $\mathrm{Pol}$ gene in $86 \%$ of acute lesions. However, it was not seen in uninvolved skin, adjacent to the HAEM lesions. The skin of healed HAEM from 1 to 3 months were shows PCR positive for the viral pol gene. ${ }^{[13]}$

In agreement with Imafuku et al., ${ }^{[15]}$ the viral DNA is cleared from the skin within 1-1.5 months of HSV lesion resolution, whereas HAEM lesional skin is still positive 1-3 months after healing. Still in agreement with these authors, the positive HSV DNA was detected in keratinocytes, germinative cells, and epithelial cells from the outer root sheath of the hair follicle and in the epithelial cover for sensory nerve endings. Using in situ reverse transcription PCR, these authors also observed the RNA signal in keratinocytes within the basal and spinous epidermal layers with a distribution similar to that of the viral DNA. This signal was cytoplasmic, probably reflecting the RNA function in translation. The Pol RNA was observed in acute but not healed HAEM lesional skin that was positive only for Pol DNA. Therefore, the HAEM lesion development is related with $\mathrm{Pol}$ gene expression. ${ }^{[15]}$ A few years ago, an international group of investigators 
started a large case-control study, the Severe Cutaneous Adverse Reactions (SCAR) study, to determine the risk factors for EM, SJS, and TEN. ${ }^{[16]}$ The SCAR study was a multinational case-control study conducted through extensive surveillance networks of about 1800 hospital departments and 120 million inhabitants of France, Germany, Italy, and Portugal from February 1, 1989, to July 31, 1995. The results of this study on a large number of patients confirm that EM on the one hand and SJS and TEN on the other hand behave as dissimilar disorders, occurring in patients with different demographic characteristics, presenting with different clinical patterns and with different risk factors. ${ }^{[16]}$

Therefore, in the current knowledge, the EM spectrum, which includes EM minor usually associated or not to HSV or others infections, can be separate from the spectrum of SJS (EM major) and of $\mathrm{TEN}^{[17]}$ that frequently are associated with drug exposition.

Few authors consider the SJS as a subclass of the EM major; ${ }^{[17]}$ however, such classification was not considered in our work due to the small number of authors with this concept. Most of the researches link SJS as a synonym of the EM major. ${ }^{[2]}$ In agreement with the current literature in the EM minor, the skin or mucous surfaces or both simultaneously can be affected. Nevertheless, only one mucous membrane is affected, usually the oral mucosa, and none additional systemic involvement is present. This revision study considers the EM minor like a distinct entity from SJS and TEN, could be associated or not to HSV.

\section{Clinical Characteristics}

Lesions of the EM minor can be persistent (continuous), cyclical (acute and self-limiting), or recurrent; the cyclical and recurrent occur mainly in the HAEM. ${ }^{[18]}$ The condition can begin with nonspecific prodromal symptoms such as headache, malaise, and fever. Symptoms last from 3 to 10 days, after which an inflammatory process yields the pathognomonic target or "iris" lesion. The EM minor skin lesions usually caused by herpes simplex are predominantly raised and distributed on the extremities and/or the face, with mucosal erosions involving one or several sites. On the other hand, lesions that are widespread flat atypical targets or macules plus blisters were mostly drug induced. ${ }^{[19]}$ In the HAEM, HSV lesions can herald the appearance of target lesions by $2-17$ days. ${ }^{[10]}$ Mainly in cases of primary HSV infection, there are frequently systemic signs and symptoms preceding the lesions, and the oral ulcers are typically much smaller. ${ }^{[19]}$ The EM minor lesions in HAEM can reach about 200 or more, evolve over 24-48 h, and are usually fixed and symmetrically distributed for about a week. These lesions also attacking more that one of the mucous surfaces could also happen simultaneously with the cutaneous involvement. In the other EM minor-induced lesions, the target lesions typically appear on the cutaneous surfaces, including palms, soles, and extensor aspect of extremities and less often on the face and neck. The lesions begin as erythematous papules, expanding 2-3 cm in diameter with a dusky purple center, a pale middle zone, and an erythematous border. Burning, pruritus, as well as central blistering or crusting may occur. $^{[10]}$ However, these lesions also may occur in one or more rarely in several mucosal surfaces. ${ }^{[20]}$ When the mucous surfaces are affected, the oral mucous membrane is commonly the most affected, being present in $25 \%-50 \%$ of all EM minor patients. ${ }^{[19]}$ Hemorrhagic crusting of the lips and ulceration predominantly of the nonkeratinized mucosa characterize oral lesions. When it affects the lips, it results in erosions or serum-hemorrhagic crusts, with pathognomonic blood-stained crusting of erosions on swollen lips, hindering the phonation, the feeding, and limiting the oral movement. ${ }^{[2]}$ The intraoral lesions attack mainly in the anterior part, being the tongue and the buccal mucous membrane, the more involved places. ${ }^{[21]}$ Although any place can be affected, the hard palate ${ }^{[21]}$ and the gum are usually preserved (only $16 \%$ of the patients). ${ }^{[2]}$

Other mucous membranes that can be affected, mainly in the HAEM cases, are the eyes, nose, genitalia, esophagus, and respiratory tract. ${ }^{[19]}$ The ocular lesions are of particular concern because they can result in scarring and progressive blindness. ${ }^{[2]}$

\section{Histological Findings}

The characteristic histopathological change of EM minor is epidermal cell death, which is termed "satellite cell necrosis," mimicking apoptotic cell death. Among some apoptosis inducers, the perforin, a pore-making granule from natural killer cells, has been suggested. ${ }^{[22]}$

Another apoptotic mechanism that can also be related is the altered expression of apoptotic regulatory proteins. The intense expression of $\mathrm{Bcl}-2$ protein by the inflammatory cells in EM minor supports a role for this protein in the maintenance or persistence of the infiltrate in submucosa. An altered or increased expression of Fas antigen throughout the epithelium in correlation with the inflammatory cell infiltrates has been reported in many skin diseases including EM minor. ${ }^{[1]}$ Some apoptosis inducers (i.e., viral infections and glucocorticoids) are common causative agents of EM minor. Epidermal cell death is also a characteristic feature of SJS and TEN. However, compared with SJS and TEN, apoptosis was far less in EM minor, maybe imply a better prognosis. ${ }^{[22]}$ In the early lesions $<24 \mathrm{~h}$ old, direct immunofluorescence showed an unspecific granular deposition of $\operatorname{IgM}, \operatorname{IgG}$, or C3 in the blood vessel walls of the upper dermis. The transient production of immune complexes plays an important role in the pathogenesis of this disease. ${ }^{[23]}$ It has been proposed that the ulcerative inflammatory lesions of the EM minor may be the result of ischemic necrosis of epithelium as a consequence of immune-mediated vasculitis. ${ }^{[11]}$ 


\section{Treatment}

Before any treatment is prescribed, possible underlying causes, such as medications, diet, infections, or systemic diseases should be determined and eliminated. ${ }^{[10]}$ The prophylactic and therapeutic use of acyclovir, in cases of HAEM, is a common practice. ${ }^{[5]}$ HSV lesions can precede the appearance of target lesions by 2-17 days, and intermittent therapy with acyclovir at a dosage of $200 \mathrm{mg}$ twice daily for 5 days, beginning at the first aura of HSV infection (i.e., local tingling and burning), can prevent and minimize the symptoms of EM. ${ }^{[10,24]}$ In patients who have recurrent EM associated with HSV, suppressive treatment using acyclovir (400 mg twice a day for 6 months) has also been effective in preventing recurrence. Newer generation antiherpes drugs such as valacyclovir hydrochloride and famciclovir are also useful in both intermittent and suppressive therapy. ${ }^{[2,10]}$ The acyclovir administration at the onset of clinical symptoms does not prevent the EM episode. It is possible that, by the time clinical symptoms are recognized, sufficient viral replication has already happened to induce a host response to the virus. ${ }^{[10]}$ Therefore, once onset the earliest symptoms, there is no effective treatment. ${ }^{[25]}$ In addition, because EM is self-limited, symptomatic therapy with antiseptics, antihistamines, and analgesics is recommended. ${ }^{[10]}$ The oral psoralen plus UV-A (PUVA) therapy has proven to be an equally effective treatment and it is anticipated that it can be used as a long-term maintenance therapy without undue concern for adverse effects. The oral PUVA therapy consists of methoxsalen and exposure of the hands and feet or the whole body to UV-A radiation using a regular schedule of three treatments each week. With the remission of the lesions, the treatment may be decreased to weekly exposures for maintenance in some months. However, generalized exacerbation of the eruption may be triggered by PUVA therapy since EM can occur as a photodermatosis. ${ }^{[26]}$ It has been showed that childhood HAEM may be unresponsive to therapy with oral acyclovir. In this case, corticosteroids should be considered as a mode of treatment. ${ }^{[5]}$ However, some authors believe that treatment with corticosteroids is not indicated in HAEM. Even though systemic corticosteroid therapy is frequently used to treat recurrent EM and it may partially suppress the disease, it may also make HAEM episodes more frequent, prolong the duration of attacks, and is associated with side effects. ${ }^{[10,25,27]}$ The use of topical and systemic corticosteroids, though, is debatable. The antimalarials (mepacrine or hydroxychloroquine) have been shown to be occasionally useful when acyclovir treatment failed ${ }^{[27]}$ and azathioprine can be used as a last resort to suppress an acute attack in patients with severe disease who do not respond to the other measures. ${ }^{[8,10,28]}$ However, it is recommended as second-line treatment due to its side effects. ${ }^{[27]}$ If this treatment fails, mycophenolate mofetil can be tried. It has been shown to be an effective and relatively safe immunosuppressive agent in recurrent EM; however, its use is limited by its high cost. ${ }^{[29]}$

\section{Controversies}

There were no particular etiologic agent, no particular clinical feature, no specific investigations, and no particular treatment pertaining to specific etiology of the lesion. If this mystery is solved, this can result in proper diagnosis and treatment of this enigmatic lesion.

\section{Conclusion}

In spite of several factors implicated, the exact etiology of EM minor is still unresolved, and although several attempts have been made, no specific criteria exist for its diagnosis. The specific pathogenic mechanisms, as well as the multifactorial development hypothesis of the lesions, are still being investigated. The treatment, except for the symptomatic therapy with antiseptics, analgesics, and antibiotics, is still being adapted for prophylaxis, control, and elimination of the possible related underlying causes.

\section{Financial support and sponsorship}

Nil.

\section{Conflicts of interest}

There are no conflicts of interest.

\section{References}

1. Greenberg MS, Glick M, Ship JA. Burket's oral medicine. In: Woo SB, Greenberg MS, editors. Ulcerative, Vesicular and Bullous Lesions. $11^{\text {th }}$ ed. Hamilton: Decker BC, Inc.; 2008. p. 53-7.

2. Carrozzo M, Togliatto M, Gandolfo S. Erythema multiforme. A heterogeneous pathologic phenotype. Minerva Stomatol 1999;48:217-6.

3. Farthing PM, Maragou P, Coates M, Tatnall F, Leigh IM, Williams DM. Characteristics of the oral lesions in patients with cutaneous recurrent erythema multiforme. J Oral Pathol Med 1995;24:9-13.

4. Huff JC, Weston WL, Tonnesen MG. Erythema multiforme: A critical review of characteristics, diagnostic criteria, and causes. J Am Acad Dermatol 1983;8:763-5.

5. Katz J, Livneh A, Shemer J, Danon YL, Peretz B. Herpes simplex-associated erythema multiforme (HAEM): A clinical therapeutic dilemma. Pediatr Dent 1999;21:359-62.

6. Kokuba H, Aurelian L, Burnett J. Herpes simplex virus associated erythema multiforme (HAEM) is mechanistically distinct from drug-induced erythema multiforme: Interferon-gamma is expressed in HAEM lesions and tumor necrosis factor-alpha in drug-induced erythema multiforme lesions. J Invest Dermatol 1999;113:808-15.

7. MacKenzie AR, Laing RB, Smith CC. Recurrent erythema multiforme following three different infections: Is genetic predisposition more important than the infectious stimulus? $\mathrm{Br} \mathrm{J}$ Dermatol 1997;137:320-1.

8. Chen CL, Chow KC, Wong CK, Liu HN, Chang YT. A study on Epstein-Barr virus in erythema multiforme. Arch Dermatol Res 1998;290:446-9.

9. Barrett AW, Scully CM, Eveson JW. Erythema multiforme involving gingiva. J Periodontol 1993;64:910-3. 
10. Singla R, Brodell RT. Erythema multiforme due to herpes simplex virus. Recurring target lesions are the clue to diagnosis. Postgrad Med 1999;106:151-4.

11. Chrysomali E, Lozada-Nur F, Dekker NP, Papanicolaou SI, Regezi JA. Apoptosis in oral erythema multiforme. Oral Surg Oral Med Oral Pathol Oral Radiol Endod 1997;83:272-80.

12. Ng PP, Sun YJ, Tan HH, Tan SH. Detection of herpes simplex virus genomic DNA in various subsets of Erythema multiforme by polymerase chain reaction. Dermatology 2003;207:349-53.

13. Kokuba H, Imafuku S, Huang S, Aurelian L, Burnett JW. Erythema multiforme lesions are associated with expression of a herpes simplex virus (HSV) gene and qualitative alterations in the HSV-specific T-cell response. Br J Dermatol 1998;138:952-64.

14. Aurelian L, Kokuba H, Burnett JW. Understanding the pathogenesis of HSV-associated erythema multiforme. Dermatology 1998;197:219-2.

15. Imafuku S, Kokuba H, Aurelian L, Burnett J. Expression of herpes simplex virus DNA fragments located in epidermal keratinocytes and germinative cells is associated with the development of erythema multiforme lesions. J Invest Dermatol 1997; 109:550-6.

16. Auquier-Dunant A, Mockenhaupt M, Naldi L, Correia O, Schröder W, Roujeau JC; SCAR Study Group. Severe Cutaneous Adverse Reactions. Correlations between clinical patterns and causes of erythema multiforme majus, Stevens-Johnson syndrome, and toxic epidermal necrolysis: Results of an international prospective study. Arch Dermatol 2002;138:1019-24.

17. Criado PR, Estevão IB, Aglio JC, et al. O espectro do eritema multiforme (eritema Multiforme minor e major) e o espectro da síndrome de Stevens-Johnson e da necróliseepidérmica tóxica (síndrome de Lyell). Rev Bras Clin Ter 2002;28:113-21.

18. Malmström M, Ruokonen $\mathrm{H}$, Konttinen $\mathrm{YT}$, Bergroth V, Segerberg-Konttinen M, Hietanen J, et al. Herpes simplex virus antigens and inflammatory cells in oral lesions in recurrent erythema multiforme. Immunoperoxidase and autoradiographic studies. Acta Derm Venereol 1990;70:405-10.

19. Manganaro AM. Erythema multiforme. Gen Dent 1996;44:164-6.

20. Neville B, Damm D, Allen C, Chi A. Oral and maxillofacial pathology. $4^{\text {th }}$ ed; W.B. Saunders company, US;2015.P.553-6.

21. Bystryn JC. Erythema multiforme with mucous membrane involvement and Stevens-Johnson syndrome are clinically different disorders. Arch Dermatol 1996;132:711-2.

22. Inachi $\mathrm{S}$, Mizutani $\mathrm{H}$, Shimizu M. Epidermal apoptotic cell death in erythema multiforme and Stevens-Johnson syndrome. Contribution of perforin-positive cell infiltration. Arch Dermatol 1997; 133:845-9.

23. Imamura S, Yanase $\mathrm{K}$, Taniguchi S, Ofuji S, Mangaoil L. Erythema multiforme: Demonstration of immune complexes in the sera and skin lesions. Br J Dermatol 1980;102:161-6.

24. Kennedy CT, Leigh IM, Ridgway HA, Wansbrough-Jones MH, Brigden D. Treatment of erythema multiforme secondary to herpes simplex by prophylactic topical acyclovir. $\mathrm{Br}$ Med $\mathrm{J}$ (Clin Res Ed) 1981;283:1360-1.

25. Weston WL, Morelli JG. Herpes simplex virus-associated erythema multiforme in prepubertal children. Arch Pediatr Adolesc Med 1997;151:1014-6.

26. Morison WL, Anhalt GJ. Therapy with oral psoralen plus UV-A for erythema multiforme. Arch Dermatol 1997;133:1465-6.

27. Sen P, Chua SH. A case of recurrent erythema multiforme and its therapeutic complications. Ann Acad Med Singapore 2004;33:793-6.

28. Schofield JK, Tatnall FM, Leigh IM. Recurrent erythema multiforme: Clinical features and treatment in a large series of patients. Br J Dermatol 1993;128:542-5.

29. Davis MD, Rogers RS $3^{\text {rd }}$, Pittelkow MR. Recurrent erythema multiforme/Stevens-Johnson syndrome: Response to mycophenolate mofetil. Arch Dermatol 2002;138:1547-50. 